IIUC STUDIES

ISSN 1813-7733

Vol.- 6, June 2010 (p 123-132)

\title{
Teaching Stress to ESL Students
}

\author{
Gazi Shahadat Hossain* \\ Sawsan Tarannum ${ }^{* *}$
}

\begin{abstract}
In English conversation, people use their voice as a complex instrument. As they use sound systems of their languages, their pronunciation usually produces infinite variations of meaning. This variation made by stress on particular syllable or word creates confusion in the minds of the ESL (English as a Second Language) students in identifying the correct meaning of the word. So it is essential for ESL students to be familiar with English stress pattern. This essay will highlight the meaning and role of stress, the ways of raising awareness among the students and the techniques of teaching it in the classroom.
\end{abstract}

Stress is the pronunciation of a word or syllable with more force than the surrounding words or syllables, i.e. when it is produced by using more air from the lungs. In other words, it is said (Harmer, J. 2001) "Stress is the term we use to describe the point in a word or phrase where pitch changes, vowels lengthen, and volume increases" (32). In a one-syllable word like 'dance', there is no problem, since at least one syllable will need these characteristics, and since there is only one syllable, we know which one it is. But a word with more than one syllable is more complex. We might stress the word 'export' on the second syllable (export) if we are using it as a verb. But if we stress the first syllable (export), the word is here a noun.

A syllable may be stressed because

(1) the accent is on that syllable, e.g. confusion, ever,

(2) the speaker wishes to emphasize (give prominence to) the syllable, e.g. I said induce not deduce.

\footnotetext{
* Assistant Professor, Dept. of English Language and Literature, Premier University, Chittagong.

** Lecturer in English, Centre for University Requirement Courses (CENURC), IIUC.
} 
Learning to pronounce a language is a very complex task and, as with any other complex learning task, the learning process of pronunciation can be made easy, and interesting, if the task is organised and structured in some way and if the learners are aware of exactly what things are involved. As on the part of students it is very difficult, so it is the teachers' job. This means that dividing the task into its components, ordering the components in manageable way and showing the learners why each component must be learnt. Learners should bear in mind that English pronunciation has various components such as sounds, stress and variation in pitch. Once learners are aware that English words have a stress pattern, that words can be pronounced in slightly different ways, that the pitch of the voice can be used to convey meaning, then they will know what to pay attention to and can build upon this awareness. This essay will investigate:

(1) the role stress plays in highlighting significant information within sentences and utterances,

(2) how we will raise students' awareness of the role stress plays,

(3) how we will teach stress to a group of students.

Correct word stress patterns are essential for the learners' production and perception of English. If a non-native speaker utters a word with the wrong stress pattern, an English listener may have great difficulty in understanding the word, although most of the individual sounds have been well pronounced. In listening also if learners of English expect a word to have a particular stress pattern, they may not recognise it when a native speaker says it. In other words, what they hear doesn't match what they have in their mental dictionary.

Kenworthy (1993) said that conversations are full of negotiations. Speakers often want to assert a fact or opinion quite strongly, deny what another speaker has said and offer a correction, or ask about alternatives and opinion in order to come to an agreement about what to do. So we can see that for the purpose of asserting, denying and correcting, the role of stress is very important. So the speakers of English often resort to stress to achieve their ends. For instance, if we want to disagree with other speakers, we can assert the opposite by repeating their words almost exactly, but changing the verb from positive to negative or vice-versa and moving the main sentence stress: 
John is funny.

John isn't funny. He is strange.

Students should be very careful of this use of stress in order to follow discussion, arguments and exchange of opinions. The ability to use stress in this way is also a useful speaking skill.

The way speakers of English utilise stress is questioning another person about alternatives, possibilities, or opinion. For instance, if one speaker uses some information and wants to check if his or her recall of that information is accurate, he uses stress: "Was it John who said that?"

For raising awareness of word and sentence stress, we will follow certain techniques. Each time we plan to introduce a new vocabulary item, we will consider what my students need to know about the word: meaning, collocation, spelling and pronunciation etc.

In the issue of pronunciation teaching, stress and unstressed syllables are very important. And there are various ways in which we can encourage a continuing awareness of stress. It is known that successful production can come through receptive awareness and that's why we need to put much emphasis on it while teaching stress. Choral and individual drilling of new words usefully combine receptive awareness and productive skills. G. Kelly (2001) opines that while it is important for teachers to appreciate that successful repetition during drilling will not successfully lead to continued accurate production, during other practice activities, or outside the classroom, it is vital to give students this opportunity to practice. At first we will try drilling words in a natural manner. But if we find that it is difficult for our students to produce exactly what we say, we will exaggerate the stressed syllable. Although this will change the characteristic of the phonemes involved, we will always come back to the unexaggerated word, once our students get the points. And it is a good idea to beat out the pattern of stress with hand or fingers or tapping with a pen on the table, speaking or singing the stress pattern.

We can indicate stress in several ways when it comes to writing a word on the board or in a handout for students:

We can write in capitals: INduce

Underline the stressed syllable: beautiful

Use boxes: object

Write circles above or below the word: resign 
Listening activities are particularly useful for students to raise awareness of stress. As teachers we should remember that pronunciation work should be seen as an integral part of what goes on in the classroom. It is important to get into the habit of indicating the stress pattern of any new word we have presented, particularly those words which I would like the students to note down, remember and use.

So stress is a feature of speech which ranges beyond the individual sound segments. While we produce utterances, our voice goes up and down, and plays a rhythmic tune. We vary not only stress but pitch also. This sort of stress and pitch gives a definite intonation to what we say. In the following sentence, in reference to the remark about the committee, we may change pitch and use a falling tone on the last syllable and so give it the force of a statement:

The committee may resign.

Or we may pronounce the last syllable with a rising tone, and thereby give our utterance the force of a question:

The committee may resign?

Or we might choose to use a rising tone to the stressed syllable in the marked version of the utterance. In this case the force of the question focuses on the committee:

The committee may resign? (Why the committee?)

While teaching stress in sentences and utterances, drilling is again very important and can be very useful for students in highlighting strong and weak forms. We can try front or back chaining or 'beating stress' with longer utterances. During the time of teaching stress, it is very important not to 'outdo' sentence stress. We need to keep in mind the context in which the sentence appears, and the meaning that the sentence is trying to convey and think about where the pitch movement occurs.

In dealing with weak forms, we will isolate these and drill on their own before putting them back into the sentence and utterance. In raising awareness of issues relating to word and sentence stress, we 
will treat these issues as part of the language being studied. we will show our students how to record stresses in their notebooks for later study which will aid students in both comprehension and language production. It is a good idea to teach students questions like 'which word is stressed?', 'Which syllable is stressed?', or 'where does the voice go up / down?' so that we can know facts about the stresses in the language item we are teaching and so that students can ask about it, if they have any problem.

Different teachers develop different habits for teaching pronunciation. We think that it is up to a teacher to discover which habit works for his students better and it is a good idea to stick to one, which comes most naturally to him or her. As a result students will be familiar with his or her teaching habits that ultimately facilitate learning.

It is said (AMEP) that pronunciation can be approached from the topdown (that is, starting with the attention to larger chunks of language) or from the bottom-up (that is, with a focus on the smaller elements, such as phonemes first). As our pronunciation teaching would be strongly integrated with the rest of language teaching, we would prefer a top down approach, because we can start with whole a chunk of language and work with this.

Unlike other languages, the word stress patterns of English are relatively unpredictable and so stress must be marked when dealing with new vocabulary. we can use big dots for stressed syllables and small dots for unstressed syllables in a single word. One set of dots is enough for the teaching of word stress, although the smaller dots are useful for marking unstressed syllables within a sentence. For marking stress when speaking we can use claps, clicks, stamps or punching gestures. If our learners have troubles with the concept of stress, we would get them to stretch an elastic band around their fingers. We will tell them to pull their fingers apart on stressed syllable and release their pressure on unstressed syllables, so that they can feel the stress physically as the elastic band stretches and releases on their fingers.

When working on word stress, we can ask my students some questions for creating awareness as mentioned by Underhill, A. (1994):

1. How do you think this is said?

2. How many sounds does it have? 
3. How do you think this is spelled?

4. How many letters does it have?

5. How many syllables are there?

6. Which syllable is stressed?

7. Do you notice a difference (understand /understand)?

8. Which sounds most English?

It is also said (AMEP) that specialised activities dedicated to the practice of particular features or pronunciation offer a useful 'off-thepeg' way of introducing and practicing pronunciation. If the right material can be found, these specialised activities are usually easy to organise and fun to do. As our aim is for learners to acquire good pronunciation along with other aspects of language, activities that can be thoroughly integrated into the usual program are also useful.

For teaching stress, we can demonstrate the importance of stress pattern in the English language by showing concern for the correct pronunciation of the names of member of the class. we can ask each student his or her name, or call out the names from the class lists. For polysyllabic names, we can make a stab at the stress placement if we don't know it already. Using rising intonation in our voice and a questioning facial expression, we can show that we are checking the names. When the student has identified himself or herself, we will show our concern for accuracy by shifting the stress to the wrong syllables. we can say, "... not" and shake my head to show we think that pronunciation is wrong. Then we will shift it back to the correct syllables. So for each student's name we will be doing something like this:

\section{T: Altaf Mahmmud?}

S: raises hand or nods.

T: not $\underline{\text { Altaf, but Altaf? }}$

\section{S: Altaf (repeating student's pronunciation)}

We can use an accompanying hand gesture to beat out the stress pattern. If student has a name, which has an English version, we can bring this in, contrasting the English writing pattern with the stress pattern of the native version. 
For variety we can use this activity in different way by using the place names and names of well-known people. We will ask the students for the names of large cities and the names of famous people. we can use various means to elicit a response, such as simple questions, picture cues and maps. As each item is named, we will establish the stress pattern as above, shifting the stress to the wrong syllable and then back again to the correct one. In the early stage of word stress, we can use the adjective 'loud'. We can ask students 'which part of the word is the loudest?' We will reserve 'stress' or 'stressed' for later stages.

Underhill said that Cuisenaire rods are one of the most powerful tools for language teaching. we can make use of a small fraction of their potential while maintaining their clarity, effectiveness and ease of use. For teaching stress, Underhill also suggests that

We should use only white and red rods.

$>$ Any rod placed on the table represents one syllable.

$>$ An unstressed syllable is represented by white rod.

$>$ A stressed syllable is represented by red rod.

Cuisenaire rods are also useful in that they can provide graphic illustration of how words and phrases are stressed. These rods of different lengths and colours we can set up to demonstrate the stress patterns of phrase and sentences as in the following example given by Harmer, J. (2001, P 32):

"I'll ring you next week

I'll ring you next WEEK

Whereas if we want to say: I'll RING you next week (= I won't come and see you), we can organise the rods like this:

I'll RING you next week."

Or I can integrate the primary/ secondary/ unstress distinction into the use of rods by using three different colours, green for primary stress, red for secondary, and white for unstressed.

It is said (AMEP fact sheet) that, learners will usually need some specific focus on sentence stress, particularly if they come from a language background with very different L1 sentence stress pattern. 
The basic concept they need to grasp is that some words are more important than others in an utterance, and that these will be stressed, while unimportant words will be unstressed. When teaching sentence stress, we can utilise two real-life situations in which restrictions on resources require a person to be selective, to include only words that are essential and to omit words that aren't. One is sending a telegram and the other is writing newspaper headlines. We can use these situations to devise activities, which will involve our students in selecting according to importance.

We know that in sending a telegram one pays by the word and most of the people react by limiting the numbers of words as much as possible. A typical activity we can make use of is from Teaching English Pronunciation by Kenworthy, J. (1993) where he says that we should begin with a written message in full. This can be provided by the teacher or written by the learners in response to a situation. An example is given here. Suppose one of the passengers has gone to the airport to catch his flight, but there is a strike and all flights are postponed for forty-eight hours. He must send a telegram to his place of work to say he will not be back on time. Now the teacher can give the group a word restriction by saying either: (1) send a telegram with as few words as possible; or (2) the cost of per word is $\mathrm{x}$ and he has only y amount of money. When the class has prepared the telegram, in groups, pairs, or individually, discuss which words they chose to omit and which to leave in and why.

We can also make use of Newspaper headlines for teaching sentence stress. Headlines often omit articles, auxiliary verbs, and prepositions in order to have more space for 'content' words that will give the gist of the news item. In class, we can present the lines and ask them what words have been left out and why.

For teaching contrastive stress, we can make use of an activity from Kelly's How to Teach Pronunciation. This short activity provides a simple way of demonstrating the effect that a shifting tonic syllable can have on the meaning of an utterance. we can write 'I love you' on the board and ask the students which syllable is stressed, eliciting that it is the word 'love'.

We can draw a stress box over the word to show this or rewrite it in capital. We will then write the same sentence up twice more. The students then work in pairs to see if they can work out any other 
possible meanings through stressing the other words in the sentence. Suggested answers are as follows:

I love you. (and I want you to know that ).

I love you. (I don't love her).

I love you. (He doesn't).

So in this essay, we have:

- considered what stress is and different levels of stress,

- considered both word and sentence stress

- considered the role that sentence plays in highlighting significant information within sentence and utterance,

- thought about how to integrate stress into teaching and how to raise students' awareness of the role it plays,

- looked at some activities for focusing on both word and sentence stress. 
IIUC Studies, Vol. 6

\section{Works-Cited}

1. AMEP Research Centre: Fact Sheet Teaching Pronunciation: Approaches and Activities, http//www.nceltr.mq.edu.au/pdamep

2. Harmer, J. The Practice of English Language Teaching.Essex: Pearson Education Ltd., 2001

3. Kelly, G. How to Teach Pronunciation.Essex: Longman, 2001

4. Kenworthy, J. Teaching English Pronunciation. Essex: Longman, 1993

5. Richards, J. Platt, J. Weber, H. Longman Dictionary of Applied Linguistics. Essex: Longman, 1987.

6. Underhill, A. Sound Foundation, Macmillan Heinemann, 1994

7. Widdowson, H. G. Linguistics. Oxford: Oxford UP, 1996 